\title{
Mesenchymal stromal cells as prophylaxis for graft-versus-host disease in haplo- identical hematopoietic stem cell transplantation recipients with severe aplastic anemia?-a systematic review and meta-analysis
}

Ruonan Li, Jingke Tu, Jingyu Zhao, Hong Pan, Liwei Fang and Jun Shi id

\begin{abstract}
Background: Mesenchymal stromal cells (MSCs) are an emerging prophylaxis option for graft-versus-host disease (GVHD) in haplo-identical hematopoietic stem cell transplantation (haplo-HSCT) recipients with severe aplastic anemia (SAA), but studies have reported inconsistent results. This systematic review and meta-analysis evaluates the efficacy of MSCs as prophylaxis for GVHD in SAA patients with haplo-HSCT.

Methods: Studies were retrieved from PubMed, EMBASE, Cochrane, Web of Science, and http://clinicaltrials.gov from establishment to February 2020. Twenty-nine single-arm studies $(n=1456)$ were included, in which eight $(n=$ 241) studies combined with MSCs and eleven $(n=1215)$ reports without MSCs in haplo-HSCT for SAA patients. The primary outcomes were the incidences of GVHD. Other outcomes included 2-year overall survival (OS) and the incidence of cytomegalovirus (CMV) infection. Odds ratios (ORs) were calculated to compare the results pooled through random or fixed effects models.

Results: Between MSCs and no MSCs groups, no significant differences were found in the pooled incidences of acute GVHD (56.0\%, 95\% Cl 48.6-63.5\% vs. 47.2\%, 95\% Cl 29.0-65.4\%; OR 1.43, 95\% Cl 0.91-2.25; $p=0.123)$, grade IIIV acute GVHD (29.8\%, 95\% Cl 24.1-35.5\% vs. 30.6\%, 95\% Cl 26.6-34.6\%; OR 0.97, 95\% Cl 0.70-1.32; $p=0.889)$, and chronic GVHD (25.4\%, 95\% Cl 19.8-31.0\% vs. 30.0\%, 95\% Cl 23.3-36.6\%; OR 0.79, 95\% Cl 0.56-1.11; $p=0.187)$. Furtherly, there was no obvious difference in 2-year OS (OR 0.98, 95\% Cl $0.60-1.61 ; p=1.000$ ) and incidence of CMV infection (OR 0.61, 95\% Cl 0.40-1.92; $p=0.018)$.

(Continued on next page)
\end{abstract}

\footnotetext{
* Correspondence: shijun@ihcams.ac.cn

Regenerative Medicine Clinic, National Clinical Research Center for Blood Diseases, State Key Laboratory of Experimental Hematology, Institute of Hematology and Blood Diseases Hospital, Chinese Academy of Medical Sciences \& Peking Union Medical College, No. 288 Nanjing Road, Heping District, Tianjin 300020, China
}

C C The Author(s). 2021 Open Access This article is licensed under a Creative Commons Attribution 4.0 International License, which permits use, sharing, adaptation, distribution and reproduction in any medium or format, as long as you give appropriate credit to the original author(s) and the source, provide a link to the Creative Commons licence, and indicate if changes were made. The images or other third party material in this article are included in the article's Creative Commons licence, unless indicated otherwise in a credit line to the material. If material is not included in the article's Creative Commons licence and your intended use is not permitted by statutory regulation or exceeds the permitted use, you will need to obtain permission directly from the copyright holder. To view a copy of this licence, visit http://creativecommons.org/licenses/by/4.0/ The Creative Commons Public Domain Dedication waiver (http://creativecommons.org/publicdomain/zero/1.0/) applies to the data made available in this article, unless otherwise stated in a credit line to the data. 
(Continued from previous page)

Conclusions: Our meta-analysis indicates that the prophylactic use of MSC co-transplantation is not an effective option for SAA patients undergoing haplo-HSCT. Hence, the general co-transplantation of MSCs for SAA haplo-HSCT recipients may lack evidence-based practice.

Keywords: Mesenchymal stromal cells, Severe aplastic anemia, Hematopoietic stem cell transplantation, Haploidentical, Graft-versus-host disease, Meta-analysis

\section{Introduction}

Severe aplastic anemia (SAA) is a life-threatening bone marrow failure syndrome characterized by pancytopenia and hypoplastic bone marrow. Hematopoietic stem cell transplantation (HSCT) has been considered as a first-line therapy for young adults [1]. However, only $20-30 \%$ acquired SAA patients realistically hope to find a human leukocyte antigen (HLA)-matched sibling donor. With the improvement of conditioning regimens, like "Beijing protocol," haplo-identical HSCT (haplo-HSCT) has recently been widely used to treat SAA patients as an alternative strategy [2]. However, the main challenges facing current haplo-HSCT usage included the risk of graft-versus-host disease (GVHD) and a higher graft failure (GF) rate [3-5]. Therefore, improving the haplo-HSCT outcomes in SAA patients is of great concern.

Mesenchymal stromal cells (MSCs) are multipotent stromal cells characterized by modulating immune and inflammation response, supporting hematopoiesis, and repairing tissues, which are widely used in haploHSCT $[6,7]$. MSCs can be isolated from many tissues, including bone marrow (BM), cord blood and umbilical cord (UC) tissues, periosteum, adipose tissue, and fetal liver $[8,9]$. According to several previous clinical studies, the application of MSCs in haplo-HSCT can decrease the incidence and severity of acute or chronic GVHD, promote facilitation of HSC engraftment, and improve OS [10-15]. However, others found that MSCs may make little or no difference in reducing the risk of GVHD and death [16-18]. Thus, these conflicting results need to be addressed urgently [19].

To the best of our knowledge, there have been some excellent clinical studies about proposing haplo-HSCT as the first-line therapy for SAA patients [20-22]. Therefore, it is of great importance to clarify key factors related to the outcomes of SAA with haploHSCT. For example, some meta-analyses compared different donor sources in haplo-HSCT, evaluating whether peripheral blood $(\mathrm{PB})$ or $\mathrm{BM}$ as graft source produces a more satisfactory outcome in SAA patients [23], while others sought the optimal conditioning regimen for haplo-HSCT in patients with SAA [24-26]. In addition, several meta-analyses have approved the efficacy of MSCs in haplo-HSCT recipients with hematological conditions, mostly in hematological malignancies [27, 28]. Nevertheless, no meta-analysis has been done to evaluate the efficacy of MSCs combined with haplo-HSCT in SAA patients so far. Therefore, we performed the first systematic review and meta-analysis to investigate the efficacy of MSC co-transplantation following HSCT in patients with SAA.

\section{Methods}

\section{Literature search}

This meta-analysis was performed according to the Preferred Reporting Items for Systematic Reviews and Meta-Analyses (PRISMA) guidelines issued in 2009 [29]. We performed a systematic literature search in PubMed, EMBASE, OVID, Web of Science, and Cochrane Central Register of Controlled Trials (CENT RAL) from inception to January 2020 with the search terms "haplo-identical hematopoietic stem cell transplantation," "mesenchymal stem cells," and "severe aplastic anemia." In addition, we searched clinical trials in http://clinicaltrials.gov with "severe aplastic anemia [condition/disease] AND (haplo-identical hematopoietic stem cell transplantation [other terms])."

\section{Study selection}

Articles in the literature were identified and data were extracted by two investigators independently. Disagreements were resolved through discussion. The reference lists of relevant studies were also hand-searched. These searches were limited to the "first generation" reference lists. We removed duplicates and reviewed titles or abstracts. Studies that met the following criteria were included: (1) phase 2 or 3 clinical trials or retrospective studies evaluating the efficacy of MSC co-transplantation following HSCT in patients with SAA, (2) cases with $>5$ patients, (3) studies with consistent criteria of observation items, and (4) studies reported a quantitative outcome of interest. Exclusion criteria were the following: (1) review papers or expert opinions, (2) individual case reports, (3) studies did not report a quantitative outcome of interest, (and 4) studies were reported in a language other than English. Meta-analyses do not involve human subjects and do not require Institutional Review Board review. 


\section{Data extraction}

Data extraction from the eligible studies was carried out independently by 2 authors. We used a standardized extraction form to extract information about the first author, year of publication, study design, number of patients, median age, median intervals from diagnosis to treatment, the prophylaxis of GVHD, the conditioning regimen, acute GVHD (aGVHD), grade II-IV aGVHD, chronic GVHD (cGVHD), engraftment rate, all-cause mortality rate, and cytomegalovirus (CMV) infection rate. Because there are differences in study design, we extracted information in accord with the following criteria: (1) if data were used in two or more studies, data from the latter study were extracted on the basis of subtracting data published in the formal study; (2) we also summarized hematologic reconstitution time without performing a meta-analysis.

\section{Quality assessment}

Two authors worked independently on quality assessment. If disagreements occurred, an adjudicator was consulted. Single-arm studies were assessed using the Newcastle-Ottawa Scale modified for cohort studies without controls, as previously used by Lopez-Olivo [30]. Potential scores ranged from 0 to 6, with higher scores indicating higher quality. The following components were assessed: selection, which includes the representativeness of the exposed cohort; ascertainment of exposure; demonstration that the outcome of interest was not present at the start of the study; and outcome, which consists of an assessment of outcome, followed up long enough for outcomes to occur, and adequacy of the followup of cohorts. Because it was a meta-analysis of single proportions, publication bias was not advisable in this study.

\section{Statistical analysis}

Data manipulation and statistical analyses were performed using Stata statistical software version 15.0 (StataCorp, College Station, TX, USA) and R software (version 3.6.3). We conducted separate analyses for single-arm retrospective researches studying the treatment outcomes of haplo-HSCT with MSCs or without MSCs. Heterogeneity between studies was evaluated via $I$-squared statistic and $p$ value. When heterogeneity was significant $(p<0.05$ or $I$-squared $>50 \%)$, a randomeffects model was adopted to pool the results. Then, $x^{2}$ tests were applied to find if there are statistical differences of pooled estimates between groups, the effect measure was the adjusted odds ratio (OR) with 95\% confidence intervals (CIs), and $p<0.05$ was defined as statistically significant. The results of the meta-analysis were graphically displayed by forest plots and heterogeneity was further explored by subgroup analysis and sensitivity analysis. Notably, the event rates can be zero or one from some studies yet they still need to be included in the analysis to represent the whole population. In such cases, the resulting distribution of proportions tends to be 0 inflated. We made good use of the Freeman-Tukey double arcsine transformation to perform normalization and variance, which can be achieved by using the metaprop module to perform fixed and random effects metaanalysis of proportions.

\section{Results \\ Search results}

We initially identified 478 potentially eligible papers from the electronic databases. After excluding 53 duplicates, records $(n=425)$ were screened by reviewing titles and abstracts and excluded according to the exclusion criteria. Finally, the remaining 61 studies were further filtrated by reading the full text. As a result, 32 records were excluded, and 29 studies met the inclusion criteria. The included studies were divided into two groups (MSCs [31-38]; no MSCs [22, 24, 25, 39-56]) based on whether they applied the MSCs or not. The selection process is illustrated in Fig. 1. Screening and evaluation were conducted independently by two reviewers with resolution of disagreement by consensus or adjudication by a third reviewer.

\section{Quality assessment}

The results of risk of bias for each study are shown in Tables 1 and 2. All studies had a score $\geq 5$, which indicates a relatively high research quality. The subjects included were representative, and ascertainment of exposure was confirmed by secure record. Outcome assessment was based on medical records, and the follow-up period was sufficient for outcomes to occur.

\section{Incidence of GVHD}

The pooled results of aGVHD, grade II-IV aGVHD, and $\mathrm{cGVHD}$ in the MSCs group and no MSCs group are summarized in Table 3. Our metaanalysis revealed no significant heterogeneity in aGVHD $\quad(I$-squared $=8.3 \%, p=0.365)$, grade II-IV aGVHD $(I$-squared $=0.0 \%, p=0.841)$, and cGVHD $(I$-squared $=18.1 \%, p=0.287)$ in the MSCs group, so fixed models were applied. By pooling studies with no significant heterogeneity, we learned that the overall incidences of aGVHD (Fig. 2a), grade II-IV aGVHD (Fig. 2c), and cGVHD (Fig. 2e) were $56.0 \%$ (95\% CI, 48.6 to $63.5 \%), 29.8 \%$ (95\% CI, 24.1 to $35.5 \%$ ), and $25.4 \%$ (95\% CI, 19.8 to $31.0 \%)$ in the MSCs group respectively, while random models were applied in no MSCs group with heterogeneity in 


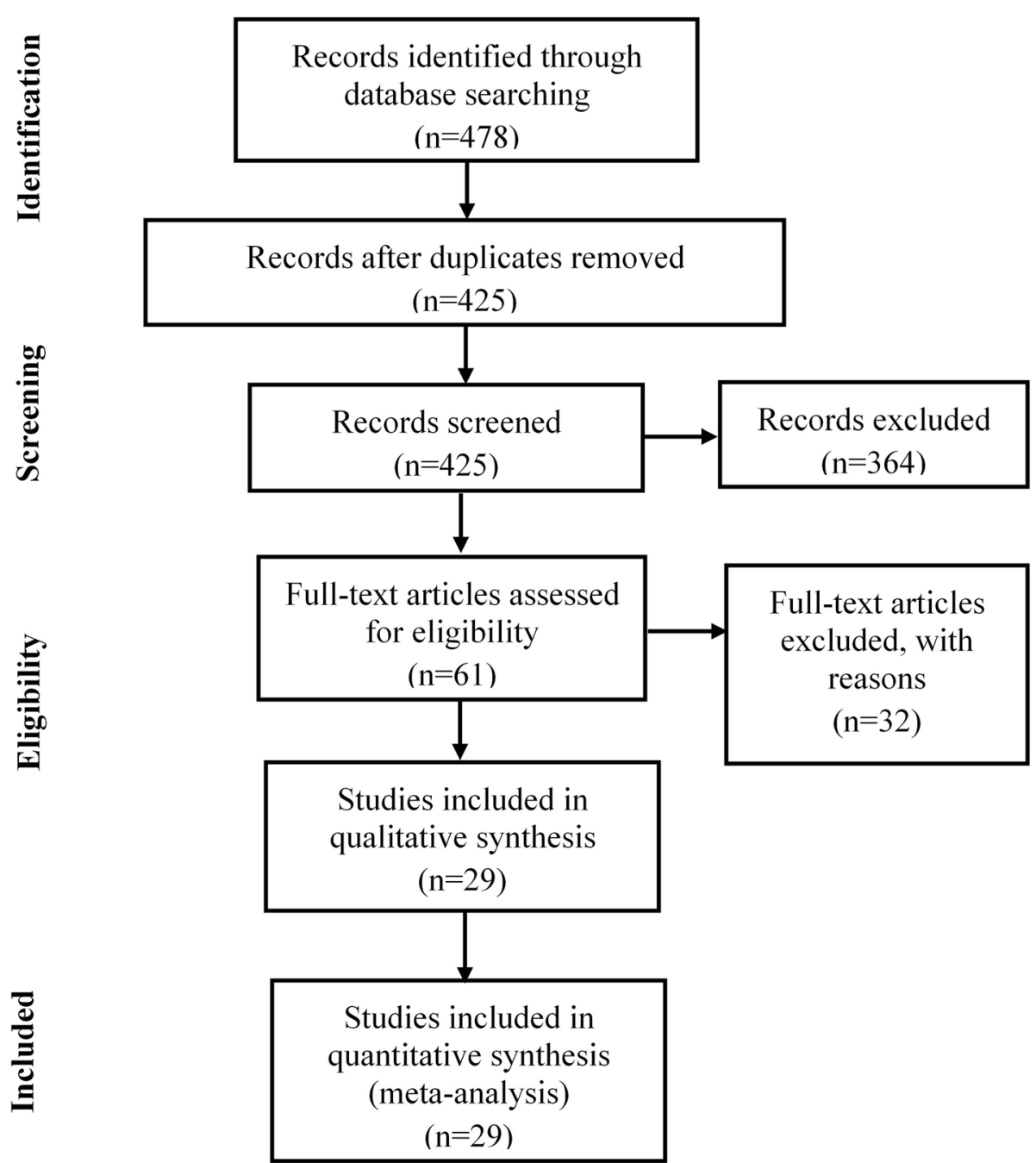

Fig. 1 PRISMA flow diagram of the systematic literature search process

aGVHD $\quad(I$-squared $=88.6 \%, \quad p=0.000), \quad$ grade $\quad$ II-IV aGVHD ( $I$-squared $=43.1 \%, p=0.022)$, and cGVHD ( $I$ squared $=81.2 \%, p<0.001)$. The overall incidences of aGVHD (Fig. 2b), grade II-IV aGVHD (Fig. 2d), and cGVHD (Fig. 2f) were $47.2 \%$ (95\% CI, 29.0 to $65.4 \%$ ), $30.6 \%$ (95\% CI, 26.6 to $34.6 \%$ ), and $30.0 \%$ (95\% CI, 23.3 to $36.6 \%)$ respectively. Results showed that there was insufficient evidence to detect a difference in the risk of aGVHD in the comparison of MSCs and no MSCs (OR 1.43, 95\% CI 0.91 to 2.25; $p=0.123$ ); the same situation was detected in grade II-IV aGVHD (OR $0.97,95 \%$ CI 0.70 to $1.32 ; p=0.889$ ) and cGVHD (OR $0.79,95 \%$ CI 0.56 to $1.11 ; p=0.187$ ) (Table 3). Subgroup analysis demonstrated no significant heterogeneity in subgroup between the use of UC-MSCs and BM-MSCs in the MSCs group (Fig. 2c, e).

\section{Overall survival}

Two-year OS were reported in 8 studies in the MSCs group and 12 studies in no MSCs group respectively without significant heterogeneity in both groups (MSCs: $I$-squared $=24.0 \%, \quad p=0.238 ; \quad$ no MSCs: $I$ squared $=20.4 \%, \quad p=0.243$ ) (Fig. 3a, b), so fixed models were applied. The pooled results of 2 -year OS were $84.9 \%$ (95\% CI, 80.4 to $89.3 \%)$ and $85.2 \%$ (95\% CI, 81.6 to $88.8 \%$ ) respectively (Fig. 3). There was no significant difference in 2-year OS in the comparison of MSCs and no MSCs (OR 0.98, 95\% CI 0.60 to $1.61 ; p=1.000$ ) (Table 3 ).

\section{Engraftment rate and $\mathrm{CMV}$ infection rate}

Our meta-analysis revealed no significant heterogeneity in engraftment rate (MSCs: $I$-squared $=0 \%, p=$ 


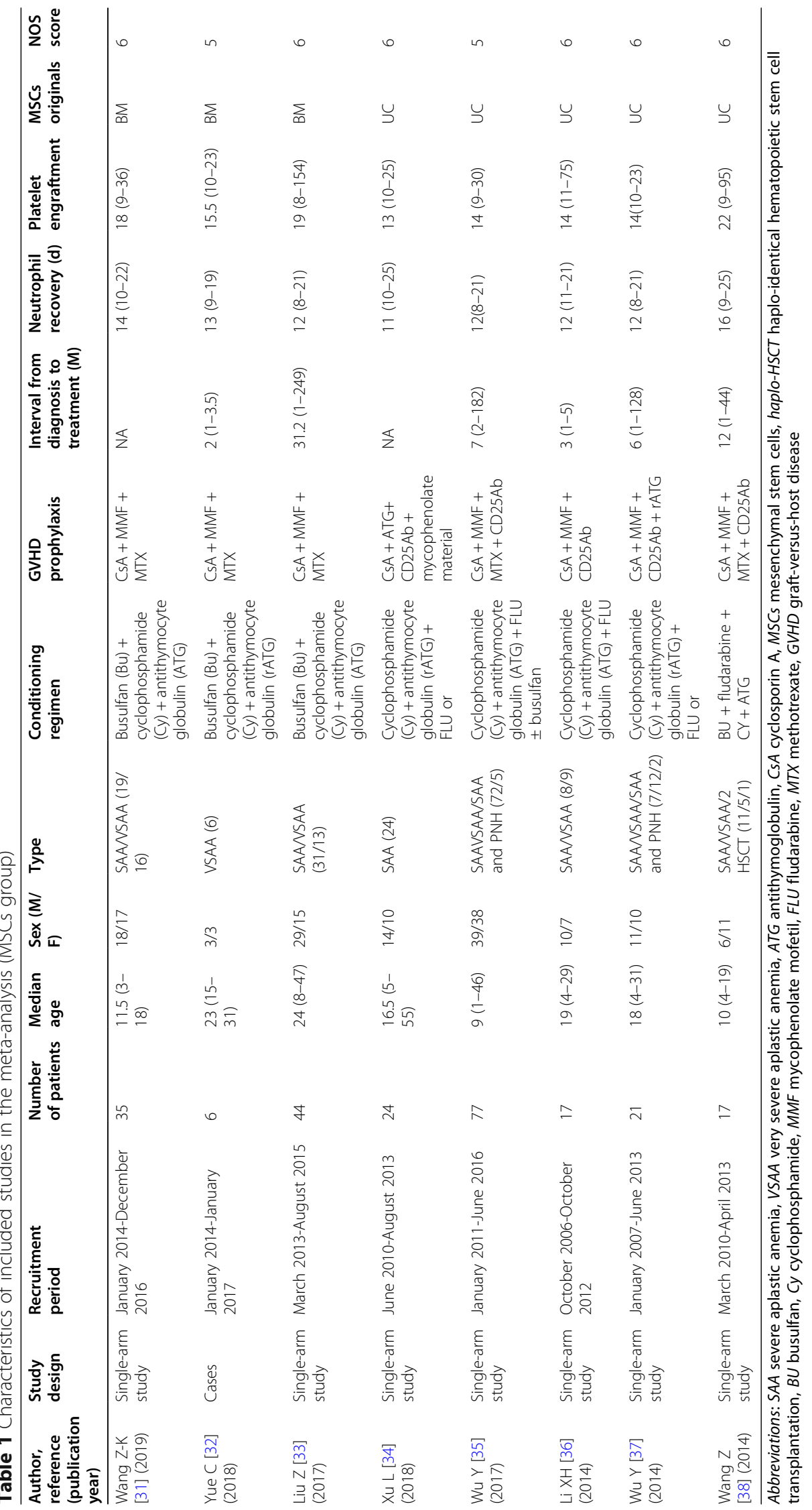




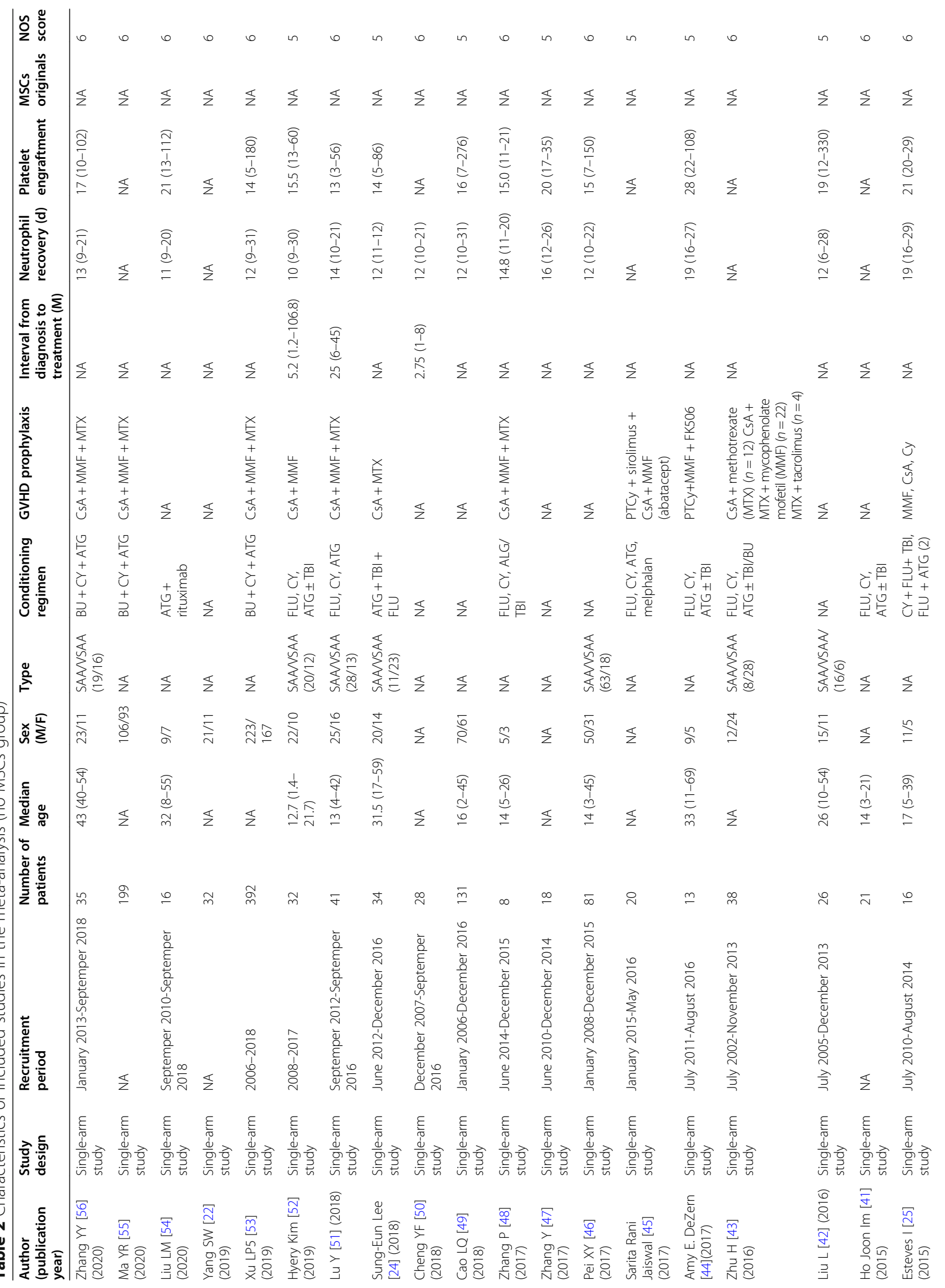




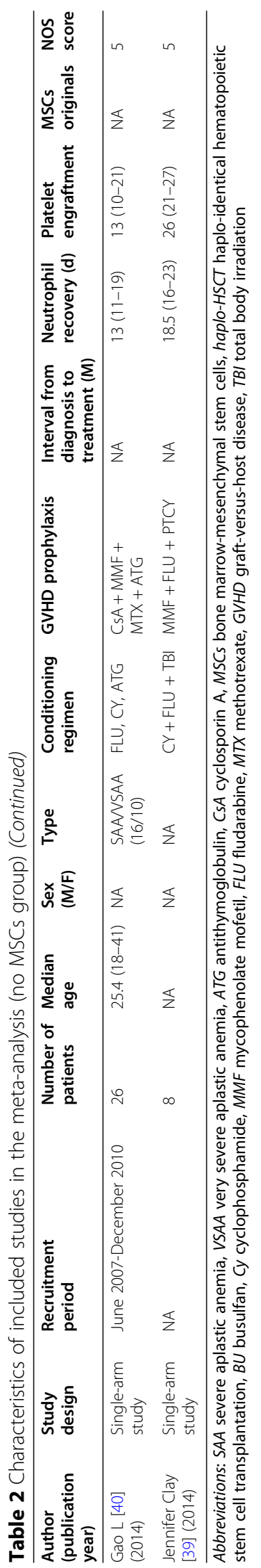


Table 3 Pooled estimates in MSCs group and no MSCs group

\begin{tabular}{|c|c|c|c|c|c|c|}
\hline Pooled estimates & Pooling model & $\begin{array}{l}\text { Number of studies, } \\
\text { haplo-HSCT + MSCs/ } \\
\text { haplo-HSCT alone }\end{array}$ & $\begin{array}{l}\text { haplo-HSCT + } \\
\text { MSCs (95\% CI) }\end{array}$ & haplo-HSCT alone $(95 \% \mathrm{CI})$ & OR (95\% Cl) & $p$ value \\
\hline aGVHD & Fixed/random & $7 / 9$ & $56.0 \%(48.6 \%, 63.5 \%)$ & $47.2 \%(29.0 \%, 65.4 \%)$ & $1.43(0.91-2.25)$ & 0.123 \\
\hline Grade II-IV aGVHD & Fixed/random & $8 / 20$ & $29.8 \%(24.1 \%, 35.5 \%)$ & $30.6 \%(26.6 \%, 34.6 \%)$ & $0.97(0.70-1.32)$ & 0.889 \\
\hline cGVHD & Fixed/random & $8 / 18$ & $25.4 \%(19.8 \%, 31.0 \%)$ & $30.0 \%(23.3 \%, 36.6 \%)$ & $0.79(0.56-1.11)$ & 0.187 \\
\hline 2-year OS & Fixed/fixed & $8 / 12$ & $84.9 \%(80.4 \%, 89.3 \%)$ & $85.2 \%(81.6 \%, 88.8 \%)$ & $0.98(0.60-1.61)$ & 1.000 \\
\hline Engraftment rate & Fixed/fixed & $8 / 17$ & $98.9 \%(96.4 \%, 100.0 \%)$ & $98.6 \%(96.5 \%, 99.8 \%)$ & $1.02(0.66-1.54)$ & 1.000 \\
\hline CMV infection rate & Random/random & $5 / 10$ & $52.4 \%(31.6-73.1 \%)$ & $64.1 \%(52.9-75.2 \%)$ & $0.61(0.40-1.92)$ & 0.018 \\
\hline
\end{tabular}

Abbreviations: GVHD graft-versus-host disease, aGVHD acute GVHD, cGVHD chronic GVHD, MSCs mesenchymal stromal cells, haplo-HSCT haplo-identical hematopoietic stem cell transplantation, $O R$ odds ratio, $O S$ overall survival, $C I$ confidence interval, $C M V$ cytomegalovirus

0; no MSCs: $I$-squared $=46.8 \%, p=0.018$ ). Four of eight studies achieved $100 \%$ hematopoietic reconstitution and full donor chimerism after haplo-HSCT with the administration of MSCs. The pooled results of engraftment rate were $98.9 \%$ (95\% CI, 96.4 to $100.0 \%$ ) and $98.6 \%$ (95\% CI, 96.5 to $99.8 \%$ ) respectively (Fig. 4). No significant difference was detected when compared MSCs with no MSCs (OR 1.02, 95\% CI 0.66 to $1.54 ; p=1.000)$. Random models were applied to pool the incidences of CMV infection because of significant heterogeneity detected in both groups, the pooled results were 52.4\% (95\% CI, 31.6 to $73.1 \%)$ and $64.1 \%(95 \% \mathrm{CI}, 52.9$ to $75.2 \%)$ respectively (Fig. 5). Likewise, no significant difference was observed (OR $0.61,95 \%$ CI 0.40 to $1.92 ; p=0.018$ ) (Table 3).

\section{Discussion}

This up-to-date meta-analysis comprehensively examined the published literature to evaluate the efficacy of co-transplantation of MSCs and haploHSCT in patients with SAA. To the best of our knowledge, this is the first meta-analysis to compare the clinical outcomes of MSCs with no MSCs in haplo-HSCT in patients with SAA. The results of our study are partially consistent with a previous meta-analysis examining the effects of MSCs posttransplantation of haplo-HSCT in hematological malignancies [15]. For example, we both concluded that MSCs make no difference in the incidences of aGVHD and CMV infection. They found a role of MSCs in reducing the incidences of cGVHD, while we did not.

Our study demonstrated no significant difference with regard to the pooled incidences of GVHD between MSCs and no MSCs groups. It is well known that GVHD remains the common and life-threatening complication limiting the widespread use of haploHSCT, as it associates with a high mortality and morbidity [57]. Since there were no controlled studies, we compared the incidence of aGVHD, grade II-IV aGVHD, and cGVHD in MSCs group and no MSCs group. Although the incidence of aGVHD was higher than no MSCs group, the incidences of grade II-IV aGVHD and cGVHD were lower than the pooled results in no MSCs group. However, no significant differences were found in pooled results between these two groups, which was different from the previous studies supporting a role of MSCs in reducing the incidence of GVHD [15, 27]. Despite these previous studies showing that MSCs are effective in GVHD prophylaxis or treatment, most of them were conducted in vitro or in hematological malignancies. Moreover, the conclusions were drawn in HSCT area without highlighting on haplo-HSCT [58-60]. Hence, MSCs may make little or no difference to the risk of GVHD compared to no MSCs in haplo-HSCT for SAA patients.

Among the MSCs group, four of eight studies achieved 100\% hematopoietic reconstitution and full donor chimerism after the application of MSCs in haplo-HSCT, which is higher than no MSCs group (4/17). Although MSCs were higher than no MSCs group with regard to the pooled results of 2-year OS and engraftment rates in our report, no statistically significant differences were found. Furthermore, it is reported that infections are the other major causes of death after haplo-HSCT in addition to GVHD [61]. We calculated the rates of death due to infection. The pooled result was $9.5 \%(95 \% \mathrm{CI}$, 5.8 to $13.1 \%$ ) in the included studies in the MSCs group, which was much lower than those reported by the Center for International Blood and Marrow Transplant Research (CIBMTR), for all haplo-HSCT transplants conducted between 2009 and 2010 (infection 13-18\%) [62]. CMV infections are opportunistic infections caused by low immune function. A reduction in CMV infection after allo-HSCT can 


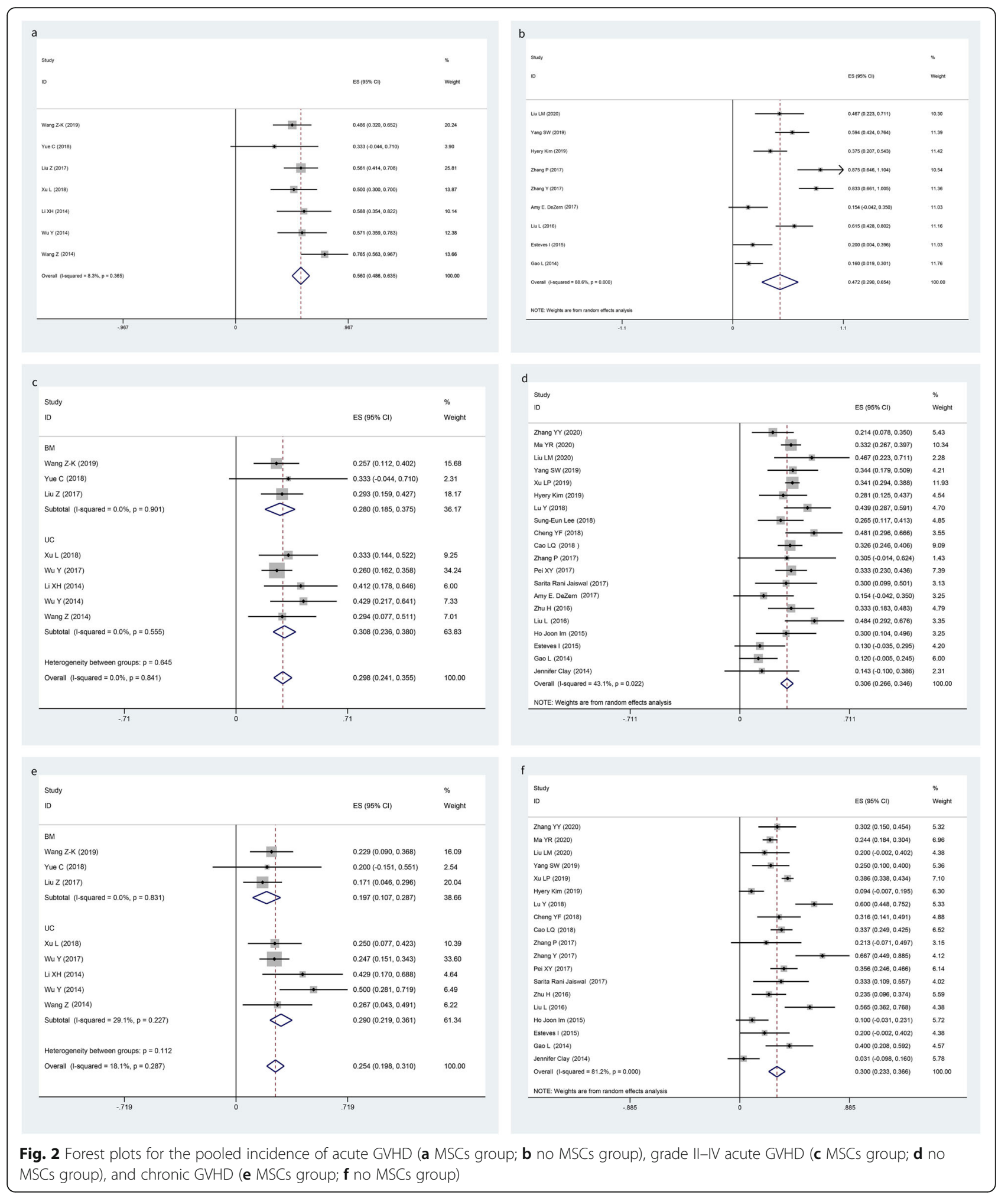

be achieved by hastening post-transplant immune reconstitution. Therefore, co-transplantation of MSCs and haplo-HSCT seemed like making no contribution to immune reconstitution in SAA patients.
It is reported that MSCs produce growth factors to aid tissue regeneration and accelerate the hematologic reconstitution [63]. The median postHSCT times to neutrophil greater than $0.5 \times 10^{9} / \mathrm{L}$ 


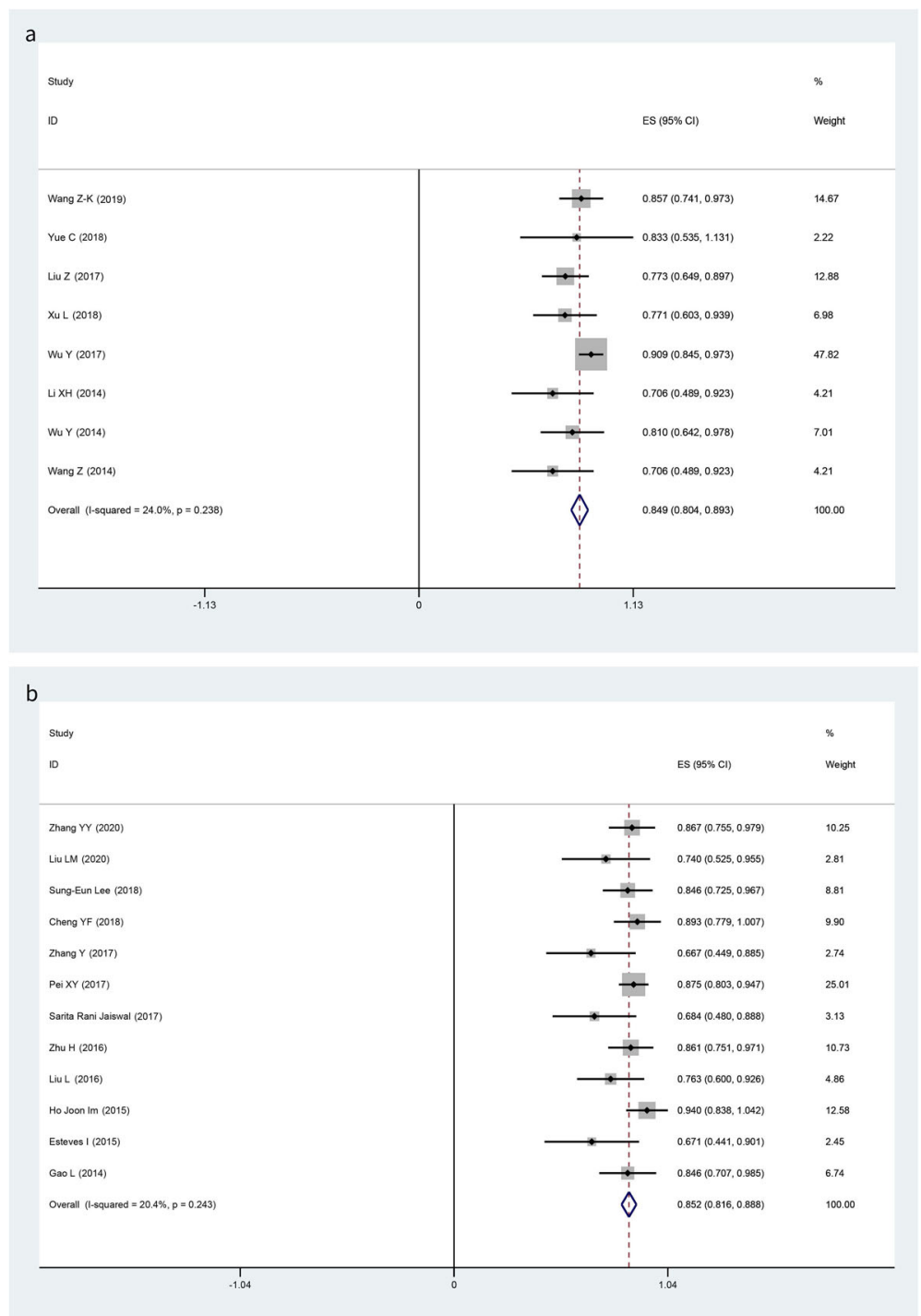

Fig. 3 Forest plots for the pooled 2-year overall survival (a MSCs group; b no MSCs group)

and platelet greater than $20 \times 10^{9} / \mathrm{L}$ were summarized and listed in Table 1 and 2 . The shortest and longest median time to achieve neutrophil engraftment and platelet engraftment were 11-14 days and 13-21 days respectively in the MSCs group and 1019 days and 13-28 days respectively in the no MSCs group. Remarkably, all studies in the MSCs group reported results descriptively and stated that they observed either rapid engraftment [37] or a similar speed of engraftment after adding MSCs [31, 32], which may demonstrate a role for MSCs in the enhancement of engraftment in SAA patients who underwent haplo-HSCT.

According to the published papers, the treatment efficacy of MSCs varies among clinical trials, and
MSC source might influence this [64]. The studies included in this meta-analysis used only BM-MSCs or UC-MSCs. Therefore, we conducted a subgroup meta-analysis for GVHD prevention according to MSC source. Consequently, the incidence of GVHD shows no significant difference with regard to the use of UC-MSCs versus BM-MSCs. Besides, we conducted "influence analysis" in Stata to explore the source of heterogeneity in no MSCs group. We could reasonably infer that studies (Jennifer et al. [39] and Gao et al. [40]) were one of the most important sources resulting in the heterogeneity of aGVHD and cGVHD respectively. Both of them were conducted in earlier years with different conditioning regimes and prophylaxis measures. 


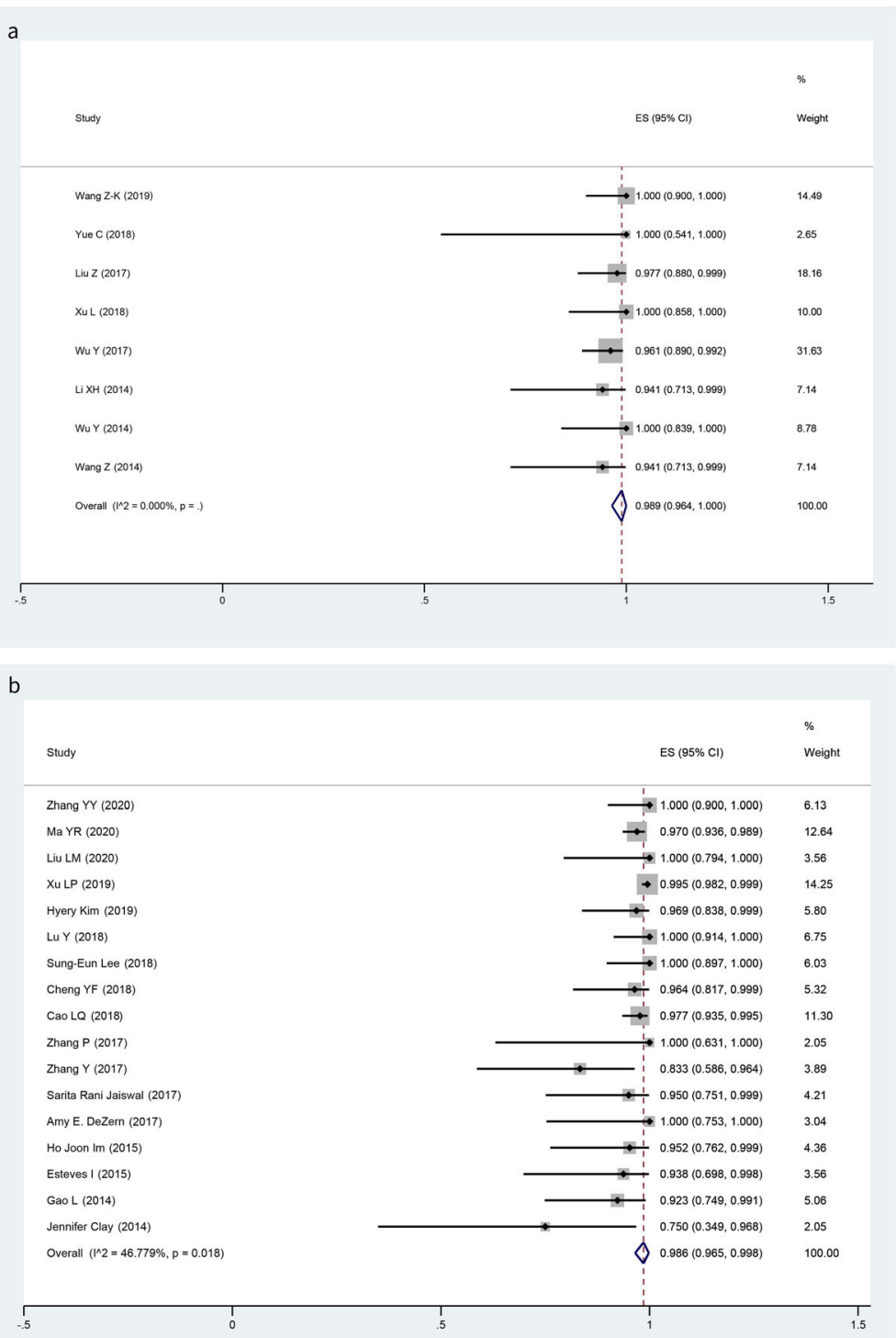

Fig. 4 Forest plots for the pooled engraftment rate (a MSCs group; b no MSCs group)

There are some limitations in our meta-analysis. First, there may be a risk of confounding biases because various baseline characteristics or cointerventions including age, gender, donor type, conditioning regimen, and MSC originals may affect the treatment outcomes in SAA patients after haploHSCT; they were not fully controlled in this study. In addition, patients in no MSCs group usually had high heterogeneity. Although we tried to decrease the bias through statistical methods, sometimes errors were unavoidable. Second, because SAA is a rare disorder, few prospective control trials between the MSCs and no MSCs group are available so far, and all the included studies had small sample sizes. Besides, all were single-arm studies and case series that lacked a control group and likely suffered from a high risk of selection bias. Last but not least, we could not assess publication bias using funnel plots because we only had single-arm studies and case series.

In conclusion, our meta-analysis indicates that the prophylactic use of MSC co-transplantation does not reduce the incidence of GVHD and improve 2year OS in patients with SAA undergoing haploHSCT. Hence, the general co-transplantation of MSCs in routine clinical practice for SAA haploHSCT recipients is not recommended. However, 


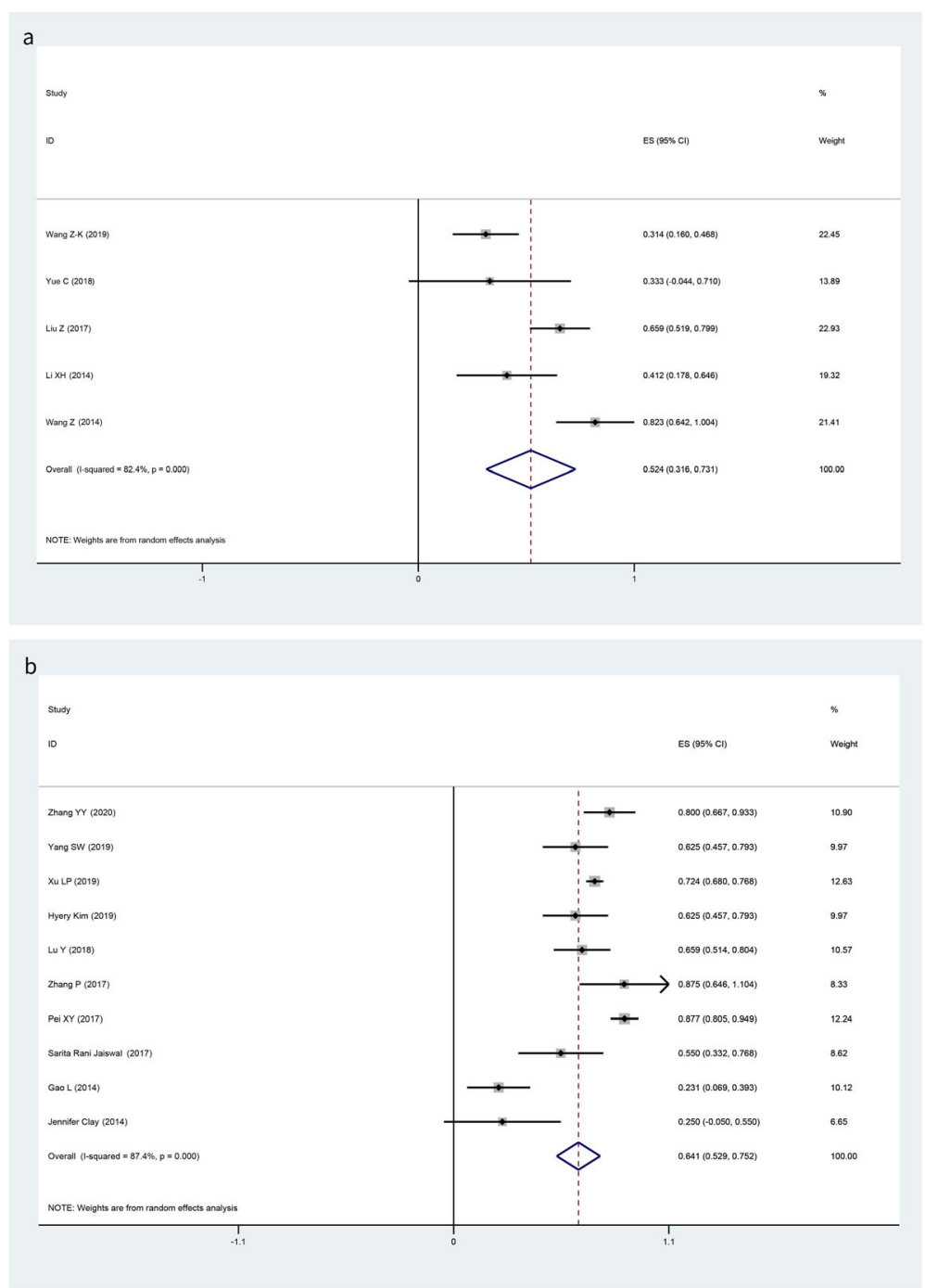

Fig. 5 Forest plots for the pooled incidences of CMV viremia (a MSCs group; b no MSCs group)

since there is no direct evidence from comparative study to support this conclusion, more prospective, randomized controlled trials (RCTs) are needed to confirm whether MSCs convey a definite benefit for haplo-HSCT for SAA patients.

\section{Acknowledgements}

Not applicable.

\section{Authors' contributions}

R.L., J.T., and J. S. conceived the study. R.L. collected and analyzed the data and wrote the paper. J.Z., H.P., and L.F. contributed to the data collection and analysis. J.S. designed the research and gave an approval of the final manuscript. The authors read and approved the final manuscript.

\section{Funding}

This work was supported by the Tianjin Municipal Science and Technology Commission Major Project (18ZXDBSY00070), the CAMS Initiative for Innovative Medicine (2017-12M-3-018), the National Natural Science Foundation of China (81670120), and the National Major Scientific and
Technological Special Project of China for "Significant New Drugs Development" (2017ZX09304024).

Availability of data and materials

All supporting data are included in the article and Additional file.

Ethics approval and consent to participate

Not applicable

Consent for publication

Not applicable

\section{Competing interests}

The authors declare that they have no competing interests.

Received: 18 October 2020 Accepted: 14 January 2021

Published online: 04 February 2021

\section{References}

1. Georges GE, Doney K, Storb R. Severe aplastic anemia: allogeneic bone marrow transplantation as first-line treatment. Blood Adv. 2018;2(15):2020-8. 
e-pub ahead of print 2018/08/16. https://doi.org/10.1182/bloodadvances. 2018021162.

2. Huang XJ, Liu DH, Liu KY, Xu LP, Chen H, Han W, et al. Haploidentical hematopoietic stem cell transplantation without in vitro T-cell depletion for the treatment of hematological malignancies. Bone Marrow Transplant. 2006;38(4):291-7. e-pub ahead of print 2006/08/03. https://doi.org/10.1038/ sj.bmt.1705445.

3. Broglie L, Margolis D, Medin JA. Yin and Yang of mesenchymal stem cells and aplastic anemia. World J Stem Cells. 2017;9(12):219-26. e-pub ahead of print 2018/01/13. https://doi.org/10.4252/wjsc.v9.112.219.

4. Passweg JR, Perez WS, Eapen M, Camitta BM, Gluckman E, Hinterberger W, et al. Bone marrow transplants from mismatched related and unrelated donors for severe aplastic anemia. Bone Marrow Transplant. 2006;37(7):6419. e-pub ahead of print 2006/02/21. https://doi.org/10.1038/sj.bmt.1705299.

5. Lv M, Chang YJ, Huang XJ. Update of the "Beijing Protocol" haplo-identical hematopoietic stem cell transplantation. Bone Marrow Transplant. 2019; 54(Suppl 2):703-7. e-pub ahead of print 2019/08/23. https://doi.org/10.1038/ s41409-019-0605-2.

6. Zhao K, Liu Q. The clinical application of mesenchymal stromal cells in hematopoietic stem cell transplantation. J Hematol Oncol. 2016;9(1):46. epub ahead of print 2016/05/20. https://doi.org/10.1186/s13045-016-0276-z.

7. Le Blanc K, Ringden O. Mesenchymal stem cells: properties and role in clinical bone marrow transplantation. Curr Opin Immunol. 2006;18(1): 586-91. e-pub ahead of print 2006/08/02. https://doi.org/10.1016/j.coi. 2006.07.004.

8. da Silva ML, Chagastelles PC, Nardi NB. Mesenchymal stem cells reside in virtually all post-natal organs and tissues. J Cell Sci. 2006; 119(Pt 11):2204-13. e-pub ahead of print 2006/05/11. https://doi.org/ $10.1242 /$ jcs.02932.

9. Kern S, Eichler H, Stoeve J, Kluter H, Bieback K. Comparative analysis of mesenchymal stem cells from bone marrow, umbilical cord blood, or adipose tissue. Stem cells (Dayton). 2006;24(5):1294-301. e-pub ahead of print 2006/01/18. https://doi.org/10.1634/stemcells.2005-0342.

10. Fang B, Song Y, Li N, Li J, Zhao RC. Cotransplantation of haploidentica mesenchymal stem cells to reduce the risk of graft failure in a patient with refractory severe aplastic anemia. Acta Haematol. 2008;119(3):162-5. e-pub ahead of print 2008/05/22. https://doi.org/10.1159/000134015.

11. Wang H, Yan H, Wang Z, Zhu L, Liu J, Guo Z. Cotransplantation of allogeneic mesenchymal and hematopoietic stem cells in children with aplastic anemia. Pediatrics. 2012;129(6):e1612-5. e-pub ahead of print 2012/ 05/09. https://doi.org/10.1542/peds.2011-2091.

12. Le Blanc K, Samuelsson H, Gustafsson B, Remberger M, Sundberg B, Arvidson J, et al. Transplantation of mesenchymal stem cells to enhance engraftment of hematopoietic stem cells. Leukemia. 2007;21(8):1733-8. epub ahead of print 2007/06/02. https://doi.org/10.1038/s.leu.2404777.

13. Lazarus HM, Koc ON, Devine SM, Curtin P, Maziarz RT, Holland HK, et al. Cotransplantation of HLA-identical sibling culture-expanded mesenchymal stem cells and hematopoietic stem cells in hematologic malignancy patients. Biol Blood Marrow Transplant. 2005;11(5):389-98. e-pub ahead of print 2005/04/23. https://doi.org/10.1016/j.bbmt.2005.02.001.

14. Morata-Tarifa C, Macias-Sanchez MDM, Gutierrez-Pizarraya A, SanchezPernaute R. Mesenchymal stromal cells for the prophylaxis and treatment of graft-versus-host disease-a meta-analysis. Stem Cell Res Ther. 2020;11(1):64. e-pub ahead of print 2020/02/20. https://doi.org/10. 1186/s13287-020-01592-z.

15. Fisher SA, Cutler A, Doree C, Brunskill SJ, Stanworth SJ, Navarrete C, et al. Mesenchymal stromal cells as treatment or prophylaxis for acute or chronic graft-versus-host disease in hematopoietic stem cell transplant (HSCT) recipients with a haematological condition. Cochrane Database Syst Rev. 2019;1:CD009768. e-pub ahead of print 2019/01/31. https://doi.org/10.1002/ 14651858.CD009768.pub2.

16. Liu K, Chen Y, Zeng Y, Xu L, Liu D, Chen H, et al. Coinfusion of mesenchymal stromal cells facilitates platelet recovery without increasing leukemia recurrence in haploidentical hematopoietic stem cell transplantation: a randomized, controlled clinical study. Stem Cells Dev. 2011;20(10):1679-85. e-pub ahead of print 2010/12/15. https://doi.org/10. 1089/scd.2010.0447.

17. Cle DV, Santana-Lemos B, Tellechea MF, Prata KL, Orellana MD, Covas DT, et al. Intravenous infusion of allogeneic mesenchymal stromal cells in refractory or relapsed aplastic anemia. Cytotherapy. 2015;17(12):1696-705. epub ahead of print 2015/11/22. https://doi.org/10.1016/j.jcyt.2015.09.006.
18. Kallekleiv M, Larun L, Bruserud O, Hatfield KJ. Co-transplantation of multipotent mesenchymal stromal cells in allogeneic hematopoietic stem cell transplantation: a systematic review and meta-analysis. Cytotherapy. 2016;18(2):172-85. e-pub ahead of print 2016/01/23. https://doi.org/10.1016/ j.jcyt.2015.11.010.

19. Galipeau J. The mesenchymal stromal cells dilemma--does a negative phase III trial of random donor mesenchymal stromal cells in steroid-resistant graft-versus-host disease represent a death knell or a bump in the road? Cytotherapy. 2013;15(1):2-8. e-pub ahead of print 2012/12/25. https://doi. org/10.1016/j.jcyt.2012.10.002

20. Xu LP, Jin S, Wang SQ, Xia LH, Bai H, Gao SJ, et al. Upfront haploidentical transplant for acquired severe aplastic anemia: registry-based comparison with matched related transplant. J Hematol Oncol. 2017;10(1):25. e-pub ahead of print 2017/01/22. https://doi.org/10.1186/s13045-017-0398-y.

21. Geng C, Liu X, Chen M, Yang C, Han B. Comparison of frontline treatment with intensive immunosuppression therapy and HLA-haploidentical hematopoietic stem cell transplantation for young patients with severe aplastic anemia - a meta analysis. Leukemia Res. 2020;88:106266. e-pub ahead of print 2019/11/20. https://doi.org/10.1016/.leukres.2019.106266.

22. Yang S, Yuan X, Ma R, Jiang L, Guo J, Zang Y, et al. Comparison of outcomes of frontline immunosuppressive therapy and frontline haploidentical hematopoietic stem cell transplantation for children with severe aplastic anemia who lack an HLA-matched sibling donor. Biol Blood Marrow Transplant. 2019;25(5):975-80. e-pub ahead of print 2019/01/19. https://doi.org/10.1016/j.bbmt.2019.01.017.

23. Yu X, Liu L, Xie Z, Dong C, Zhao L, Zhang J, et al. Bone marrow versus peripheral blood as a graft source for haploidentical donor transplantation in adults using post-transplant cyclophosphamide-a systematic review and meta-analysis. Crit Rev Oncol Hematol. 2019;133:120-8. e-pub ahead of print 2019/01/22. https://doi.org/10.1016/j.critrevonc.2018.05.017.

24. Lee S-E, Park SS, Jeon Y-W, Yoon J-H, Cho B-S, Eom K-S, et al. Optimal conditioning regimen for haplo-identical stem cell transplantation in adult patients with acquired severe aplastic anemia: prospective de-escalation study of TBI and ATG dose. Am J Hematol. 2018;93(11):1368-75. https://doi. org/10.1002/ajh.25257.

25. Esteves I, Bonfim C, Pasquini R, Funke V, Pereira NF, Rocha V, et al. Haploidentical BMT and post-transplant Cy for severe aplastic anemia: a multicenter retrospective study. Bone Marrow Transplant. 2015;50(5):685-9. e-pub ahead of print 2015/03/03. https://doi.org/10.1038/bmt.2015.20.

26. Bacigalupo A, Giammarco S. Haploidentical donor transplants for severe aplastic anemia. Semin Hematol. 2019;56(3):190-3. e-pub ahead of print 2019/06/17. https://doi.org/10.1053/j.seminhematol.2019.03.004.

27. Zhao L, Chen S, Yang P, Cao H, Li L. The role of mesenchymal stem cells in hematopoietic stem cell transplantation: prevention and treatment of graftversus-host disease. Stem Cell Res Ther. 2019;10(1):182. e-pub ahead of print 2019/06/23. https://doi.org/10.1186/s13287-019-1287-9.

28. Wu KH, Wu HP, Chan CK, Hwang SM, Peng CT, Chao YH. The role of mesenchymal stem cells in hematopoietic stem cell transplantation: from bench to bedsides. Cell Transplant. 2013;22(4):723-9. e-pub ahead of print 2012/10/17. https://doi.org/10.3727/096368912×655217.

29. A L, DG A, J T, C M, PC G, JP I et al. The PRISMA statement for reporting systematic reviews and meta-analyses of studies that evaluate health care interventions: explanation and elaboration. 2009; 6(7): e1000100. doi: https://doi.org/10.1371/journal.pmed.1000100

30. Lopez-Olivo MA, Pratt G, Palla SL, Salahudeen A. Rasburicase in tumor lysis syndrome of the adult: a systematic review and meta-analysis. Am J Kidney Dis. 2013;62(3):481-92. e-pub ahead of print 2013/05/21. https://doi.org/10. 1053/j.ajkd.2013.02.378.

31. Wang Z, Yu H, Cao F, Liu Z, Liu Z, Feng W, et al. Donor-derived marrow mesenchymal stromal cell co-transplantation following a haploidentical hematopoietic stem cell transplantation trail to treat severe aplastic anemia in children. Ann Hematol. 2019;98(2):473-9. e-pub ahead of print 2018/10/ 21. https://doi.org/10.1007/s00277-018-3523-2.

32. Yue C, Ding Y, Gao Y, Li L, Pang Y, Liu Z, et al. Cotransplantation of haploidentical hematopoietic stem cells and allogeneic bone marrowderived mesenchymal stromal cells as a first-line treatment in very severe aplastic anemia patients with refractory infections. Eur J Haematol. 2018; 100(6):624-9. e-pub ahead of print 2018/03/14. https://doi.org/10.1111/ejh. 13060.

33. $X u$ L, Liu Z, Wu Y, Yang $X, C a o$ Y, Li X, et al. Clinical evaluation of haploidentical hematopoietic combined with human umbilical cord-derived 
mesenchymal stem cells in severe aplastic anemia. Eur J Med Res. 2018; 23(1):12. e-pub ahead of print 2018/03/02. https://doi.org/10.1186/s40001018-0311-3.

34. Liu Z, Zhang Y, Xiao H, Yao Z, Zhang H, Liu Q, et al. Cotransplantation of bone marrow-derived mesenchymal stem cells in haploidentical hematopoietic stem cell transplantation in patients with severe aplastic anemia: an interim summary for a multicenter phase II trial results. Bone Marrow Transplant. 2017;52(5):704-10. e-pub ahead of print 2017/01/10. https://doi.org/10.1038/bmt.2016.347.

35. Wu Y, Cao Y, Li X, Xu L, Wang Z, Liu P, et al. Cotransplantation of haploidentical hematopoietic and umbilical cord mesenchymal stem cells for severe aplastic anemia: successful engraftment and mild GVHD. Stem Cell Res. 2014;12(1):132-8. e-pub ahead of print 2013/11/05. https://doi.org/ 10.1016/j.scr.2013.10.001.

36. Wang Z, Zheng X, Yan H, Li D, Wang H. Good outcome of haploidentical hematopoietic SCT as a salvage therapy in children and adolescents with acquired severe aplastic anemia. Bone Marrow Transplant. 2014;49(12):14815. e-pub ahead of print 2014/08/19. https://doi.org/10.1038/bmt.2014.187.

37. Li XH, Gao CJ, Da WM, Cao YB, Wang ZH, Xu LX, et al. Reduced intensity conditioning, combined transplantation of haploidentical hematopoietic stem cells and mesenchymal stem cells in patients with severe aplastic anemia. Plos One. 2014;9(3):e89666. e-pub ahead of print 2014/03/07. https://doi.org/10.1371/journal.pone.0089666.

38. Yamei W, Rongmu L, Yongbin C, Yingjian S, Xiaohong L, Xiaomei Z, et al. Improved outcome of haploidentical transplantation in severe aplastic anemia using reduced-intensity fludarabine-based conditioning. Oncotarget. 2017;8(48):83817-30. e-pub ahead of print 2017/11/16. https://doi.org/10. 18632/oncotarget.19745.

39. Clay J, Kulasekararaj AG, Potter V, Grimaldi F, McLornan D, Raj K, et al. Nonmyeloablative peripheral blood haploidentical stem cell transplantation for refractory severe aplastic anemia. Biol Blood Marrow Transplant. 2014; 20(11):1711-6. e-pub ahead of print 2014/07/13. https://doi.org/10.1016/j. bbmt.2014.06.028.

40. Gao L, Li Y, Zhang Y, Chen X, Gao L, Zhang C, et al. Long-term outcome of HLA-haploidentical hematopoietic SCT without in vitro T-cell depletion for adult severe aplastic anemia after modified conditioning and supportive therapy. Bone Marrow Transplant. 2014;49(4):519-24. e-pub ahead of print 2014/01/28. https://doi.org/10.1038/bmt.2013.224.

41. Im HJ, Koh KN, Seo JJ. Haploidentical hematopoietic stem cell transplantation in children and adolescents with acquired severe aplastic anemia. Korean J Pediatr. 2015;58(6):199-205. e-pub ahead of print 2015/07/ 28. https://doi.org/10.3345/kjp.2015.58.6.199.

42. Liu L, Wang $X$, Jin S, Hao L, Zhang Y, Zhang X, et al. Haploidentical hematopoietic stem cell transplantation for nonresponders to immunosuppressive therapy against acquired severe aplastic anemia. Bone Marrow Transplant. 2016;51(3):424-7. e-pub ahead of print 2015/10/20. https://doi.org/10.1038/bmt.2015.249.

43. Zhu H, Luo RM, Luan Z, Lee V, Zhu YP, Luo CJ, et al. Unmanipulated haploidentical hematopoietic stem cell transplantation for children with severe aplastic anemia. Br J Haematol. 2016;174(5):799-805. e-pub ahead of print 2016/06/07. https://doi.org/10.1111/bjh.14110.

44. DeZern AE, Zahurak M, Symons H, Cooke K, Jones RJ, Brodsky RA. Alternative donor transplantation with high-dose post-transplantation cyclophosphamide for refractory severe aplastic anemia. Biol Blood Marrow Transplant. 2017;23(3):498-504. e-pub ahead of print 2016/12/26. https://doi. org/10.1016/j.bbmt.2016.12.628.

45. Jaiswal SR, Bhakuni P, Zaman S, Bansal S, Bharadwaj P, Bhargava S, et al. T cell costimulation blockade promotes transplantation tolerance in combination with sirolimus and post-transplantation cyclophosphamide for haploidentical transplantation in children with severe aplastic anemia. Transpl Immunol. 2017;43-44:54-9. e-pub ahead of print 2017/08/15. https://doi.org/10.1016/j.trim.2017.07.004.

46. Pei $X Y$, Zhao $X Y, X u L P$, Wang $Y$, Zhang $X H$, Chang YJ, et al. Immune reconstitution in patients with acquired severe aplastic anemia after haploidentical stem cell transplantation. Bone Marrow Transplant. 2017; 52(11):1556-62. e-pub ahead of print 2017/08/15. https://doi.org/10.1038/ bmt.2017.174.

47. $Y Z, Z$ G, XD L, XP H, KY, P C et al. Comparison of haploidentical hematopoietic stem cell transplantation and immunosuppressive therapy for the treatment of acquired severe aplastic anemia in pediatric patients. 2017; 24(2): e196-e201. doi: https://doi.org/10.1097/mjt.0000000000000366
48. Zhang P, Feng K, Xue Y, Zhang CX, Wang Y, Li XL. Clinical applications of haploidentical hematopoietic stem cell transplantation in severe aplastic anemia. Eur Rev Med Pharmacol Sci. 2017;21(1):155-61 e-pub ahead of print 2017/01/26.

49. Cao LQ, Xu LP, Zhang XH, Wang Y, Liu YR, Liu KY, et al. Relationship of cell compositions in allografts with outcomes after haploidentical transplantation for acquired severe aplastic anemia: effects of CD34(+) and CD14(+) cell doses. Chin Med J (Engl). 2018;131(18):2185-92. e-pub ahead of print 2018/09/12. https://doi.org/10.4103/0366-6999.240810.

50. Cheng $Y, X u$ Z, Zhang Y, Wu J, Wang F, Mo X, et al. First-line choice for severe aplastic anemia in children: transplantation from a haploidentical donor vs immunosuppressive therapy. Clin Transplant. 2018;32(2) e-pub ahead of print 2018/01/04. https://doi.org/10.1111/ctr.13179.

51. Lu Y, Sun RJ, Zhao YL, Xiong M, Cao XY, Zhang JP, et al. Unmanipulated haploidentical hematopoietic stem cell transplantation achieved outcomes comparable with matched unrelated donor transplantation in young acquired severe aplastic anemia. Biol Blood Marrow Transplant. 2018;24(9): 1881-7. e-pub ahead of print 2018/05/18. https://doi.org/10.1016/j.bbmt. 2018.05.015.

52. Kim H, Im HJ, Koh KN, Kang SH, Yoo JW, Choi ES, et al. Comparable outcome with a faster engraftment of optimized haploidentical hematopoietic stem cell transplantation compared with transplantations from other donor types in pediatric acquired aplastic anemia. Biol Blood Marrow Transplant. 2019;25(5):965-74. e-pub ahead of print 2019/01/15. https://doi.org/10.1016/j.bbmt.2019.01.010.

53. Xu LP, Wang SQ, Ma YR, Gao SJ, Cheng YF, Zhang YY, et al. Who is the best haploidentical donor for acquired severe aplastic anemia? Experience from a multicenter study. J Hematol Oncol. 2019;12(1):87. e-pub ahead of print 2019/09/04. https://doi.org/10.1186/s13045-019-0775-9.

54. Liu L, Zhang Y, Liu S, Zhou H, Wang Q, Qiu H, et al. Outcomes of conditioning with rabbit antithymocyte globulin and rituximab in haploidentical hematopoietic stem cell transplantation in patients with severe aplastic anemia. Bone Marrow Transplant. 2020. e-pub ahead of print 2020/01/22. https://doi.org/10.1038/s41409-020-0788-6.

55. Ma YR, Wang WJ, Cheng YF, Zhang YY, Mo XD, Han TT, et al. Impact of ABO incompatibility on outcomes after haploidentical hematopoietic stem cell transplantation for severe aplastic anemia. Bone Marrow Transplant. 2020. epub ahead of print 2020/01/15. https://doi.org/10.1038/s41409-020-0779-7.

56. Zhang YY, Mo WJ, Zuo YY, Zhou M, Zhang XH, Wang Y, et al. Comparable survival outcome between transplantation from haploidentical donor and matched related donor or unrelated donor for severe aplastic anemia patients aged 40 years and older: a retrospective multicenter cohort study. Clin Transplant. 2020:e13810. e-pub ahead of print 2020/02/06. https://doi. org/10.1111/ctr.13810.

57. Xu LP, Zhang XH, Wang FR, Mo XD, Han TT, Han W, et al. Haploidentical transplantation for pediatric patients with acquired severe aplastic anemia. Bone Marrow Transplant. 2017;52(3):381-7. e-pub ahead of print 2016/12/ 13. https://doi.org/10.1038/bmt.2016.281.

58. Puissant B, Barreau C, Bourin P, Clavel C, Corre J, Bousquet C et al. Immunomodulatory effect of human adipose tissue-derived adult stem cells: comparison with bone marrow mesenchymal stem cells. $\mathrm{Br} J$ Haematol. 2005; 129(1):118-29. https://doi.org/10.1111/j.1365-2141.2005. 05409.x

59. Corcione A, Benvenuto F, Ferretti E, Giunti D, Cappiello V, Cazzanti F, et al. Human mesenchymal stem cells modulate B-cell functions. Blood. 2006; 107(1):367-72. e-pub ahead of print 2005/09/06. https://doi.org/10.1182/ blood-2005-07-2657.

60. Wang L, Zhu CY, Ma DX, Gu ZY, Xu CC, Wang FY, et al. Efficacy and safety of mesenchymal stromal cells for the prophylaxis of chronic graft-versushost disease after allogeneic hematopoietic stem cell transplantation: a meta-analysis of randomized controlled trials. Ann Hematol. 2018;97(10): 1941-50. e-pub ahead of print 2018/06/28. https://doi.org/10.1007/s00277018-3384-8

61. Wingard JR, Majhail NS, Brazauskas R, Wang Z, Sobocinski KA, Jacobsohn D, et al. Long-term survival and late deaths after allogeneic hematopoietic cell transplantation. J Clin Oncol. 2011;29(16):2230-9. e-pub ahead of print 2011/04/06. https://doi.org/10.1200/jco.2010.33.7212.

62. Pasquini MC, Wang Z, Horowitz MM, Gale RP. 2010 report from the Center for International Blood and Marrow Transplant Research (CIBMTR): current uses and outcomes of hematopoietic cell transplants for blood and bone marrow disorders. Clin Transplant 2010;8:87-105. e-pub ahead of print 2010/01/01. https://terasaki.org/store/CH8-Pasquini. 
63. Caplan Al, Dennis JE. Mesenchymal stem cells as trophic mediators. J Cell Biochem. 2006;98(5):1076-84. e-pub ahead of print 2006/04/19. https://doi. org/10.1002/jcb.20886.

64. Kim EJ, Kim N, Cho SG. The potential use of mesenchymal stem cells in hematopoietic stem cell transplantation. Exp Mol Med. 2013;45:e2. e-pub ahead of print 2013/01/12. https://doi.org/10.1038/emm.2013.2.

\section{Publisher's Note}

Springer Nature remains neutral with regard to jurisdictional claims in published maps and institutional affiliations.

Ready to submit your research? Choose BMC and benefit from:

- fast, convenient online submission

- thorough peer review by experienced researchers in your field

- rapid publication on acceptance

- support for research data, including large and complex data types

- gold Open Access which fosters wider collaboration and increased citations

- maximum visibility for your research: over $100 \mathrm{M}$ website views per year

At BMC, research is always in progress.

Learn more biomedcentral.com/submissions 